\title{
Evidence for water ice on the Moon: Results for anomalous polar craters from the LRO Mini-RF imaging radar
}

\author{
P. D. Spudis, ${ }^{1}$ D. B. J. Bussey, ${ }^{2}$ S. M. Baloga, ${ }^{3}$ J. T. S. Cahill, ${ }^{2}$ L. S. Glaze, ${ }^{4}$ \\ G. W. Patterson, ${ }^{2}$ R. K. Raney, ${ }^{2}$ T. W. Thompson, ${ }^{5}$ B. J. Thomson, ${ }^{6}$ and E. A. Ustinov ${ }^{5}$ \\ Received 6 December 2012; revised 28 August 2013; accepted 9 September 2013; published 3 October 2013.
}

[1] The Mini-RF radar instrument on the Lunar Reconnaissance Orbiter spacecraft mapped both lunar poles in two different RF wavelengths (complete mapping at $12.6 \mathrm{~cm} \mathrm{~S}$-band and partial mapping at $4.2 \mathrm{~cm} \mathrm{X-band)} \mathrm{in} \mathrm{two} \mathrm{look} \mathrm{directions,} \mathrm{removing} \mathrm{much} \mathrm{of} \mathrm{the} \mathrm{ambiguity}$ of previous Earth- and spacecraft-based radar mapping of the Moon's polar regions. The poles are typical highland terrain, showing expected values of radar cross section (albedo) and circular polarization ratio (CPR). Most fresh craters display high values of CPR in and outside the crater rim; the pattern of these CPR distributions is consistent with high levels of wavelength-scale surface roughness associated with the presence of block fields, impact melt flows, and fallback breccia. A different class of polar crater exhibits high CPR only in their interiors, interiors that are both permanently dark and very cold (less than $100 \mathrm{~K}$ ). Application of scattering models developed previously suggests that these anomalously high-CPR deposits exhibit behavior consistent with the presence of water ice. If this interpretation is correct, then both poles may contain several hundred million tons of water in the form of relatively "clean" ice, all within the upper couple of meters of the lunar surface. The existence of significant water ice deposits enables both long-term human habitation of the Moon and the creation of a permanent cislunar space transportation system based upon the harvest and use of lunar propellant.

Citation: Spudis, P. D., et al. (2013), Evidence for water ice on the Moon: Results for anomalous polar craters from the LRO Mini-RF imaging radar, J. Geophys. Res. Planets, 118, 2016-2029, doi:10.1002/jgre.20156.

\section{Introduction}

[2] The existence of ice in the polar cold traps of the Moon has been postulated for many years [e.g., Watson et al., 1961; Arnold, 1979] because of a combination of the Moon's small obliquity $\left(\sim 1.5^{\circ}\right)$ and the large variation in topographic relief near the poles. These two factors result in large areas (more than $30,000 \mathrm{~km}^{2}$ at both poles) [McGovern et al., 2013] that remain in permanent darkness and are thus very cold [Vasavada et al., 1999; Paige et al., 2010b]. Images from the Clementine global mapping mission revealed large areas of darkness near the south pole of the Moon [Shoemaker et al., 1994]. Because the spatial extent of darkness was

Additional supporting information may be found in the online version of this article.

${ }^{1}$ Lunar and Planetary Institute, Houston, Texas, USA.

${ }^{2}$ Johns Hopkins University Applied Physics Laboratory, Laurel, Maryland, USA.

${ }^{3}$ Proxemy Research, Laytonsville, Maryland, USA.

${ }^{4}$ NASA Goddard Spaceflight Center, Greenbelt, Maryland, USA.

${ }^{5}$ Jet Propulsion Laboratory, California Institute of Technology, Pasadena, California, USA.

${ }^{6}$ Center for Remote Sensing, Boston University, Boston, Massachusetts, USA.

Corresponding author: P. D. Spudis, Lunar and Planetary Institute, 3600 Bay Area Blvd., Houston, TX 77058, USA. (spudis@lpi.usra.edu)

(C)2013. American Geophysical Union. All Rights Reserved. 2169-9097/13/10.1002/jgre.20156 great, the Clementine team was able to improvise an experiment using the spacecraft transmitter to actively probe the dark areas near the poles with RF waves $(2273 \mathrm{MHz}$, $\lambda=13.2 \mathrm{~cm}$ ), receiving the echoes on Earth through the Goldstone Deep Space Network antenna [Nozette et al., 1996]. This experiment found slightly elevated circular polarization ratio (CPR); see below and also Campbell [2002] as a function of beta (phase) angle around the dark region near the south pole. The Clementine team interpreted this result as indicating the presence of water ice on the upper wall of the crater Shackleton, near the pole. Subsequently, the Lunar Prospector neutron spectrometer found low levels of epithermal neutron flux near both poles, interpreted as indication of elevated hydrogen concentration there [Feldman et al., 1998, 2000].

[3] The hypothesis that water ice is present near the poles was explored by a number of studies that used Earth-based radio-telescopes to create radar images of the Moon [e.g., Stacy et al., 1997; Campbell et al., 2006]. These studies also found areas displaying high CPR, but the authors argued that such material occurs both within and outside of the permanently dark areas of the poles and is thus likely to be caused by surface roughness. Thus, they concluded that the lunar poles do not display water ice deposits that are detectable by means of radar backscatter [Campbell et al., 2006]. Yet another study of reprocessed Clementine bistatic data failed to find an enhancement in the south polar CPR data [Simpson and Tyler, 1999]. However, the Clementine team 
Table 1. Properties of Mini-RF Imaging Radar Instrument (After Raney et al. [2011])

\begin{tabular}{|c|c|}
\hline Mini-RF & Specification \\
\hline Instrument mass (kg) & 14 \\
\hline DC power $(\mathrm{W})$ & 150 \\
\hline RF power (avg. W) & 25 \\
\hline Orbital altitude (km) & 50 \\
\hline Polarization-transmit & Left-circular \\
\hline Polarization-receive & $H$-linear and $V$-linear, coherently \\
\hline Antenna area $\left(\mathrm{m}^{2}\right)$ & 1.1 \\
\hline Resolution-baseline (m) & 150 \\
\hline Resolution-zoom (m) & 15 (azimuth); 30 (range) \\
\hline Looks-baseline & 16 \\
\hline Looks-zoom & 8 \\
\hline Swath width $(\mathrm{km})$ & $\sim 10$ (baseline); $\sim 6$ (zoom) \\
\hline Incidence look angle $\left(^{\circ}\right)$ & 48 \\
\hline Sensitivity $\left(\mathrm{NEqS}_{0}\right)(\mathrm{dB})$ & -30 and -25 (baseline), -25 and -18 (zoom) \\
\hline Wavelength $(\mathrm{cm})$ & $12.6(\mathrm{~S}-$ band $), 4.2(\mathrm{X}$-band $)$ \\
\hline Frequency (MHz) & 2380 (S-band), 7140 (X-band) \\
\hline
\end{tabular}

reexamined all of the then-available data (Arecibo Earthbased radar, Clementine bistatic results, and Lunar Prospector (LP) neutron data) and concluded that although no single piece of information was definitive, the preponderance of evidence indicated that water ice had probably been detected near the south pole of the Moon [Nozette et al., 2001].

[4] The resolution of this issue was considered to be important for both science and the future exploration of the Moon [National Research Council, 2007]. The Lunar Reconnaissance Orbiter (LRO) mission payload was optimized to provide an abundance and diversity of data and information on the environment and deposits of the lunar polar regions [Chin et al., 2007]. The Mini-RF instrument is a synthetic aperture imaging radar that flew on both the Indian Space Research Organisation's Chandrayaan-1 (also called Mini-SAR (for miniature synthetic aperture radar) on that mission only) [Spudis et al., 2010] and on NASA's Lunar Reconnaissance Orbiter spacecraft [Spudis et al., 2009; Nozette et al., 2010; Raney et al., 2011]. Mini-RF was specifically designed to map the polar regions of the Moon, including the permanently dark, "cold-trap" areas, and characterize the RF properties and physical nature of the deposits there. We report here on the initial results of our analysis and search for water ice at the poles of the Moon from data returned by the Mini-RF instrument on LRO.

\section{Experiment Design and Instrument Description}

[5] The original concept for the Mini-RF radar was patterned after conventional Earth-based radar astronomical instruments, which transmit right- or left-circular polarization and receive both senses of circular polarization, resulting in same-sense circular (SC) and opposite-sense circular (OC) image pairs. The Mini-RF flight instrument had to meet stringent mass and power constraints as well as accommodate a dual-linearly-polarized $(H$ and $V$ ) antenna design as part of the technology demonstration theme of the experiment [Nozette et al., 2010; Raney et al., 2011]. Thus, an unusual analytical approach to look for ice was developed for the Mini-RF experiment [Raney, 2007].

[6] Traditionally, a key parameter used to determine if ice is present is the circular polarization ratio (CPR). This quantity is defined to be the magnitude of the same sense (i.e., the left or right sense of the transmitted circular polarization) divided by the opposite sense polarized signals that are received. Ice deposits are known to have high CPR [e.g., Ostro, 2002; Campbell, 2002] caused by both volumetric backscatter and the coherent backscatter opposition effect (CBOE) [Mishchenko, 1992; Peters, 1992; Black et al., 2001; Nozette et al., 2001], an interferometeric enhancement of backscatter seen at very low beta (phase) angles. Surface scattering from dry, fine-grained planetary regolith typically has CPR less than unity [Campbell, 2002; Heggy et al., 2007], with increasing CPR seen in geologic units that have high degrees of surface roughness at scales similar to the wavelength of the imaging radar [Campbell, 2002, 2012, section 5.9].

[7] Mini-RF transmits a left-circular polarized signal and receives coherently horizontal and vertical linear polarizations. This hybrid architecture preserves all of the information conveyed by the reflected signals [Raney, 2007; Raney et al., 2011]. From these data, the four polarization Stokes parameters of the backscattered field are fully recoverable. These characterizations provide additional information to classify the nature of the diffuse backscatter signal. While our dual-polarization, monostatic imaging radar cannot uniquely determine the presence of ice, in conjunction with supporting data sets from other instruments, we can determine if ice is a plausible explanation for unusual deposits in the lunar polar regions or whether it is more likely to result from a high density of wavelength-scale (decimeter) rocks on the lunar surface.

[8] The LRO Mini-RF instrument obtained data at two wavebands, S-band $(2380 \mathrm{MHz}, \lambda=12.6 \mathrm{~cm})$ or X-band $(7140 \mathrm{MHz}, \lambda=4.2 \mathrm{~cm})$ with an illumination center incidence angle of $48^{\circ}$ (Table 1). The principal imaging frequency (S-band) was selected to be compatible with the highest resolution data obtained for the lunar poles from Earth-based radar imaging. The second frequency (X-band) is also in common use in the radar astronomy community for lunar studies [e.g., Zisk et al., 1974] and still fits within the controlling bandwidth of the transmitter. The radar used burst mode in which temporally separated groups of pulses are transmitted. Burst length (i.e., the time transmitting) determines the azimuth resolution of the image data, and burst period (i.e., interburst time) determines the number of looks (Table 1).

[9] Image strips from Mini-RF have multilook spatial resolution of $30 \mathrm{~m}$ ("zoom mode") or $150 \mathrm{~m}$ ("baseline mode"). Because the instrument looks off-nadir and covers swaths parallel to but offset from the ground track of the spacecraft, there is a gap in SAR coverage within a couple of degrees of latitude around both poles. Portions of these gaps in coverage were filled by both the wander of the polar orbiting spacecraft ground track caused by the inclination of the Moon's spin axis (about $1.5^{\circ}$ every 2 weeks) and by rolling the spacecraft slightly to obtain high-incidence angle SAR images. Our data products include nearly complete $(>98 \%)$ coverage in zoom (high resolution) S-band within $20^{\circ}$ of both polar regions of the Moon ( $15 \mathrm{~m} /$ pixel) in both east- and west-looking directions as well as about $68 \%$ surface coverage of midlatitudes and equatorial latitudes between $70^{\circ} \mathrm{N}$ and $70^{\circ} \mathrm{S}$. In addition, we obtained significant X-band baseline coverage of the north polar area to permit cross-comparison of the two data sets. Areas with high-CPR measurements at both wavebands data are coincident with areas previously shown to be high in CPR in agreement with some previously obtained Earth- 


\section{SPUDIS ET AL.: EVIDENCE FOR ICE ON THE MOON}
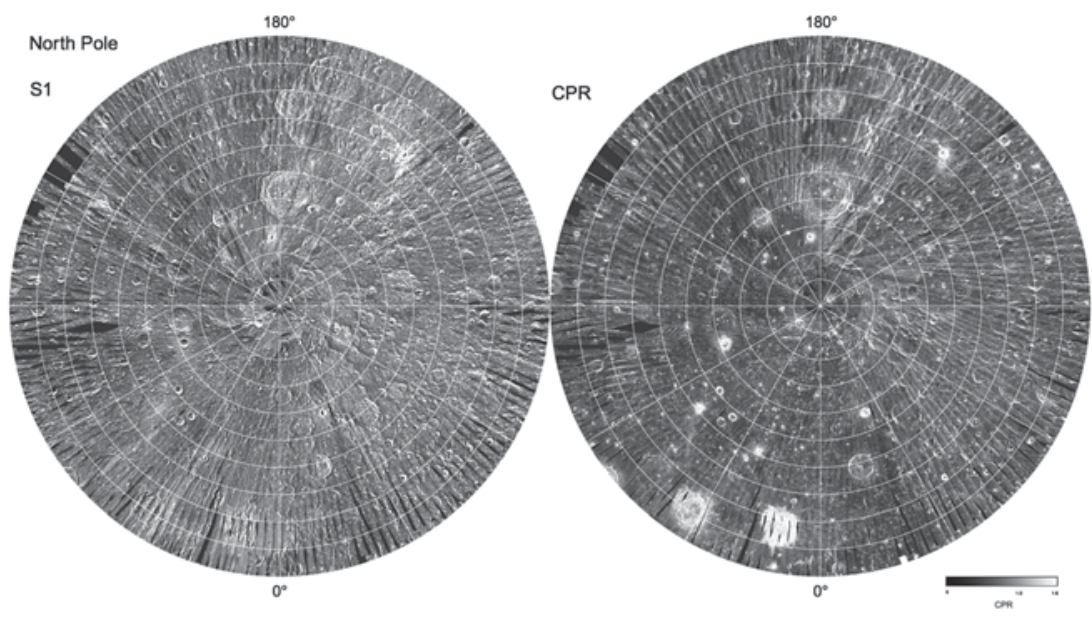

Figure 1. North polar region of the Moon, from $70^{\circ} \mathrm{N}$ to the pole. (left) $\mathrm{S} 1$ is the total reflected power SAR image; (right) CPR shows typical values for the lunar surface, including fresh craters. Grid spacing is $30^{\circ}$ of longitude, $2^{\circ}$ of latitude. Combination of east- and west-looking mosaics.

based radar data [Campbell et al., 2010; Carter et al., 2012]. The radar images consist of the four Stokes parameters and derived maps of CPR as well as other Stokes-derived products, including degree of linear polarization [Raney, 2007; Raney et al., 2011].

\section{Data Coverage and Quality}

[10] Image mosaics of the north and south poles of the Moon are shown in Figures 1 and 2. Both SAR radar albedo for the Stokes parameter S1 and CPR maps are shown. The central coverage gap is evident from the elliptical dark regions near both poles; smaller gaps are evident near the edges of the mosaics. Supplementary coverage is available for these central areas with selected low-incidence, off-nadir SAR observations covering the craters Peary and Whipple in the north and the crater Shackleton in the south. Some of these data were taken at incidence angles other than $48^{\circ}$ and are not included in the synoptic mosaics shown in Figures 1 and 2.

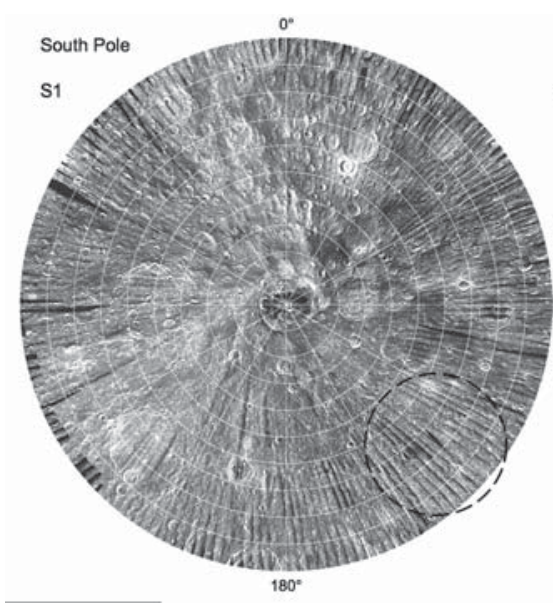

[11] Our initial processing shows a gradient of intensity in the range direction across most of the SAR strips. This artifact reflects imperfect knowledge of the polarimetric pattern of the Mini-RF antenna and can be mitigated through modeling and additional SAR processing. The gradient is evident as a radial spoke-like pattern of brightness in the mosaics. No conclusions are affected by this intensity gradient. The quoted values of radar cross section and CPR cited in this paper were taken near the center of a given individual SAR image strip, not from the mosaic product; such areas are small in relation to the swath width and are minimally affected by the intensity gradient. Additionally, we take relative measurements of a given crater within a single strip and do not mix these data with measurements taken on different image strips.

[12] Comparison of radar cross section and CPR values of the same area seen in two different look directions shows the two data sets to be in good agreement, except for obvious slope effects caused by the reversal of imaging perspective (Figure 3). CPR values from the Mini-RF S-band have been

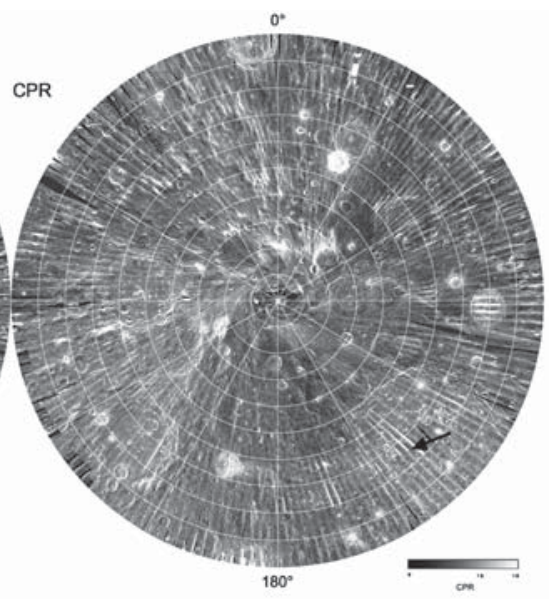

Figure 2. South polar region of the Moon, from $70^{\circ} \mathrm{S}$ to the pole. (left) $\mathrm{S} 1$ is the total reflected power SAR image; (right) CPR shows typical values for the lunar surface, including fresh craters. Grid spacing is $30^{\circ}$ of longitude, $2^{\circ}$ of latitude. Combination of east- and west-looking mosaics. Rim of the Schrödinger basin indicated by dashed line (left); arrow indicates low CPR associated with dark halo pyroclastic deposit (right). 


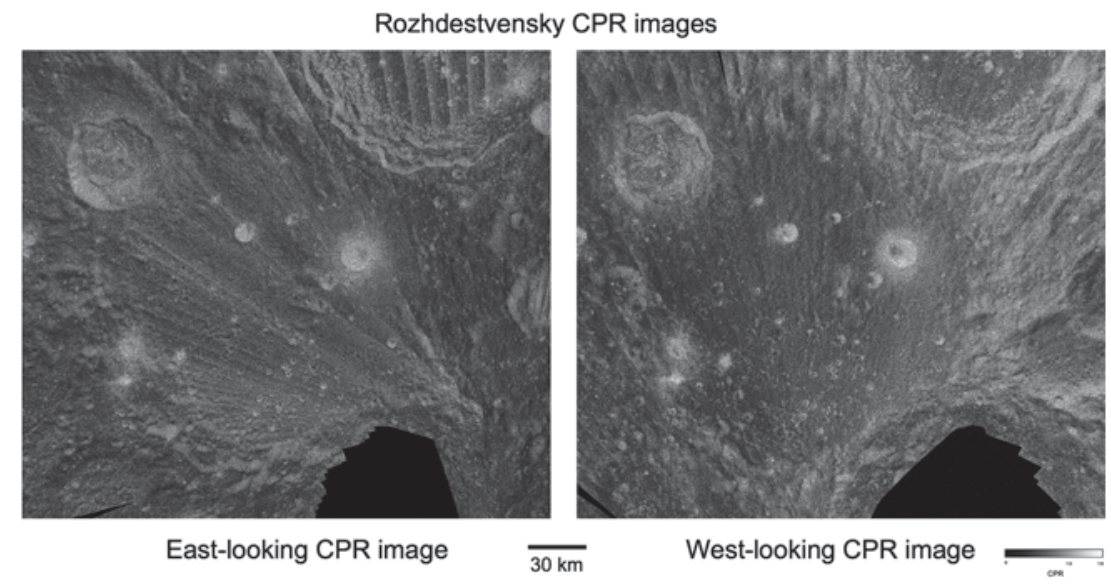

Figure 3. Two images of the crater Rozhdestvensky $\left(85^{\circ} \mathrm{N}, 155^{\circ} \mathrm{W} ; 180 \mathrm{~km}\right.$ diameter $)$ with opposite radar-look directions. The floor of this pre-Nectarian crater shows smaller superposed craters with high-CPR deposits. These deposits show the same CPR values regardless of look direction.

compared to values obtained from Earth-based radar images and yield comparable values for the same targets, after differences in incidence angle are accounted for. For example, the measured CPR from Mini-RF of the LCROSS impact target site on the floor of Cabaeus near the south pole is estimated to be $0.38 \pm 0.23$ at $48^{\circ}$ incidence [Neish et al., 2011]; this value may be compared with Arecibo CPR estimates of $\sim 0.2$ at $80^{\circ}$ incidence [Campbell et al., 2006]. A comparison of Arecibo and Mini-RF CPR in areas where the Earth-Moon geometry results in similar incidence angles for both systems can be found in the Glushko and Aristillus areas of the Moon [Carter et al., 2012]. Here the incidence angles of Mini-RF and Earth-based radar are nearly identical; crater impact melt and ejecta deposits have measured Mini-RF CPR values within 0.05 of the values determined from Earth-based radar [Campbell et al., 2010; Carter et al., 2012].

[13] The most useful data for studying polar features are the S-band zoom-mode images, which have resolution of $15 \mathrm{~m}$ in azimuth and $30 \mathrm{~m}$ in range (Table 1). We have found through analysis of the returned data that Mini-RF had an effective number of looks of about 6.7 [C.D. Neish, 2010, unpublished], as opposed to the planned 8 looks [Raney et al., 2011]. To extract high-quality CPR measurements, these data were averaged into $60 \mathrm{~m}$ pixel areas, transforming the original $7.5 \mathrm{~m}, 7$ look pixels into $60 \mathrm{~m}, 49$ look pixels. This averaging reduces radar speckle [Campbell, 2002] and gives an estimated precision for the CPR measurements of approximately 0.15 [Neish et al., 2011]. LRO Mini-RF images are greater than a factor of two better in resolution than the Mini-SAR images obtained by Chandrayaan-1 [Spudis et al., 2010] with higher signal-to-noise for better analysis of CPR values and their distribution. To aid in geological interpretation, we have also studied the characteristics of certain features that are covered by X-band baseline $(150 \mathrm{~m}$ resolution; Table 1) SAR images to determine their properties at a shorter wavelength than the systematic S-band zoom mapping.

\section{Results}

[14] Both poles of the Moon consist of highlands terrain [Lucchitta, 1978; Wilhelms et al., 1979; Wilhelms, 1987] with no evident mare deposits. The north polar area straddles two major geological provinces with the near side north being part of a distal portion of the ejecta blanket of the Imbrium basin, while the northern far side is part of a very ancient terra crustal province [Lucchitta, 1978]. The northern near side is dominated by large, ancient pre-Nectarian craters, mostly filled with Cayley-like smooth plains deposits. Numerous basin secondaries (mostly from Imbrium) are evident; some of these features are possibly secondaries of the Orientale basin [Campbell et al., 2010].

[15] The south polar region is dominated by the presence of the enormous ( $\sim 2600 \mathrm{~km}$ diameter) ancient (preNectarian) South Pole-Aitken basin [see e.g., Wilhelms et al., 1979; Spudis et al., 1994; Spudis et al., 2008], which covers most of the southern far side and partly extends onto the near side. Large massifs that make up the rim crest of this basin display steep slopes that appear either very bright or very dark, depending upon whether they are tilted toward or away from the Mini-RF instrument. For this reason, the SAR mosaic of the southern polar area has a large dynamic range in brightness, but this appearance merely reflects the large-scale topographic variation of South Pole-Aitken basin terrain in this area. The young (Imbrian/Nectarian) two-ring Schrödinger basin $\left(320 \mathrm{~km}\right.$ diameter; $\left.75^{\circ} \mathrm{S}, 133^{\circ} \mathrm{E}\right)$ is clearly discernible in the mosaics of the south pole (Figure 2). This impact structure features a small volcanic vent on its floor, which is seen in the radar image by very low CPR values where the dark, pyroclastic deposits occur [Shoemaker et al., 1994; Carter et al., 2009]. Abundant secondary craters from the Orientale basin cover the south polar area [Spudis et al., 2009]. Both polar regions contain large amounts of permanently shadowed terrain, thought on the basis of theory to be very cold (less than $100 \mathrm{~K}$ ) [Vasavada et al., 1999; Paige et al., 2010a] and subsequently shown from Diviner data to be as cold as $25 \mathrm{~K}$ in some areas [Paige et al., $2010 \mathrm{~b}$ ] and thus, are located where water ice might be stable for geologically long periods of time $(>1 \mathrm{Ga})$ [Vasavada et al., 1999].

[16] The polar regions display radar backscatter properties typical for the highland areas of the Moon [e.g., Campbell et al., 2006; Spudis et al., 2010], with average circular polarization ratio $(\mathrm{CPR})$ values of $0.48 \pm 0.3$ for most terrain 
Main L

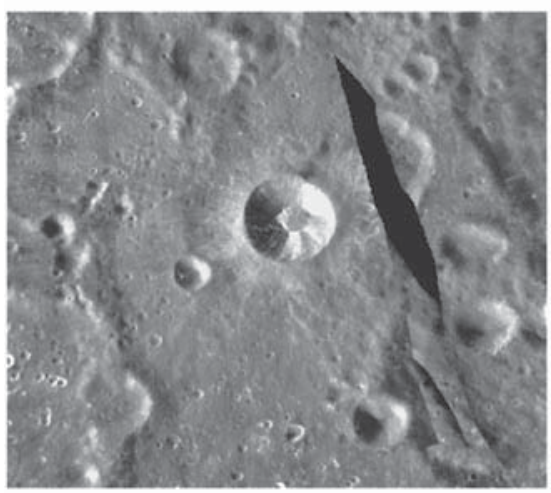

S1

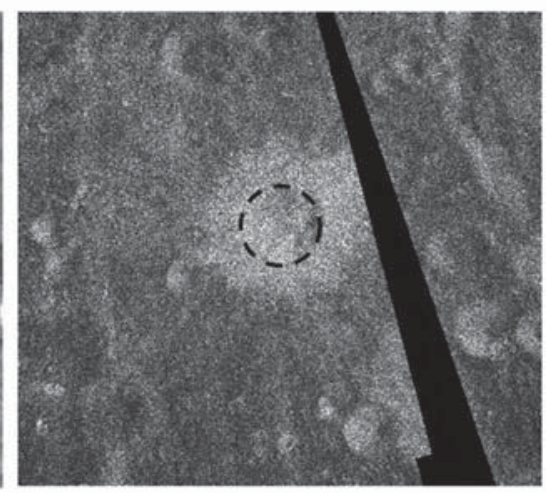

CPR

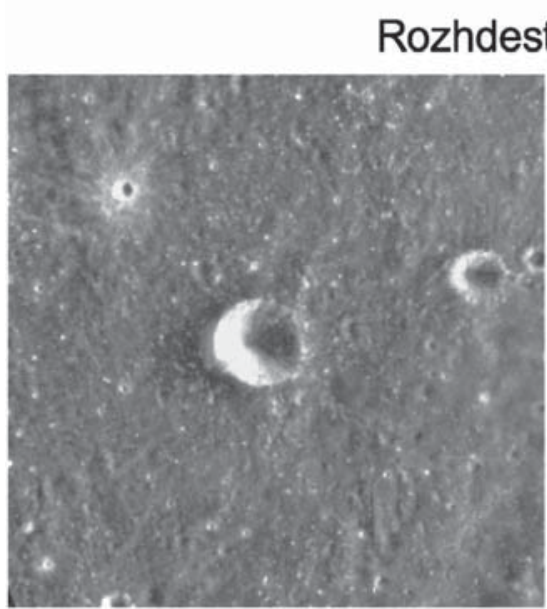

S1

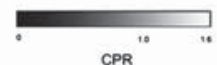

CPR

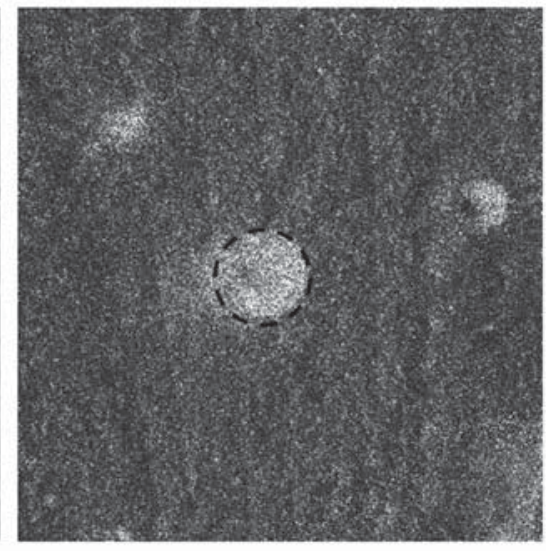

CPR

Figure 4. (top row) Main L (14 km diameter; $\left.81.4^{\circ} \mathrm{N}, 22.6^{\circ} \mathrm{E}\right)$ is a "normal" fresh, young crater showing nearly identical high CPR both interior and exterior to its rim crest (dashed circle). (bottom row) Rozhdestvensky N (9 km diameter; $\left.84.0^{\circ} \mathrm{N}, 202.6^{\circ} \mathrm{E}\right)$ is a polar anomalous crater showing high CPR only within its rim crest (dashed circle on CPR image).

[Neish et al., 2011], increasing to greater than 1.0 for the deposits associated with young, fresh impact craters. These high-CPR values likely reflect the high degree of surface roughness associated with these fresh features [e.g., Campbell et al., 2006; Spudis et al., 2010; Carter et al., 2012]. A typical fresh crater is the Copernican-aged Main L (14 km diameter; $81.4^{\circ} \mathrm{N}, 22.6^{\circ} \mathrm{E}$ ) (Figure 4) [Spudis et al., 2010]. Main L displays a crisp, continuous rim crest, unmodified by superposed craters, and has elevated CPR, with a mean value of about $0.87 \pm 0.45$ for all deposits within a crater radius of the rim crest (Figure 4). Peak CPR values within the crater floor exceed 1.8, but are more typically 0.9-1.2. Notably, the high-CPR values for Main L and other fresh lunar craters are found both inside and outside their rim crests (Figure 4) [Spudis et al., 2010]. This relation is as expected for fresh, young crater deposits, which consist of rough, blocky ejecta, flows of impact melt, and extensive block fields [e.g., Hörz et al., 1991; Wilhelms, 1987], as such features occur both within and outside of the crater rim. Over time, these fresh features erode through burial by other deposits and the continual bombardment of micrometeorites that eventually grind down the surface rocks into regolith [Hörz et al., 1991]. As these processes are effectively isotropic, similar states of degradation should be evident for crater deposits of a given age in either polar or nonpolar locations.

[17] A surprising finding during analysis of the initial CPR maps from the Chandrayaan-1 Mini-SAR was that some polar craters show high-CPR deposits only in the crater interior, but have low, "background" CPR values in adjacent deposits beyond their rims. Spudis et al. [2010] called these features "anomalous" craters on the grounds that they do not show the progressive deterioration of impact deposits evident in normal impact craters. An example of an anomalous crater is Rozhdestvensky $\mathrm{N}$ (our informal name, based on the Whitaker [1999] nomenclature scheme), a $9 \mathrm{~km}$ diameter crater $\left(84.0^{\circ} \mathrm{N}, 202.6^{\circ} \mathrm{E}\right.$; Figures 4 and 5) located on the floor of Rozhdestvensky. This crater is about the same relative age $\left(2.1 \pm 0.3 / \mathrm{km}^{2}\right.$ for $\left.D>100 \mathrm{~m}\right)$ and preservation state as Main L, which has a crater density of $1.9 \pm 0.3 / \mathrm{km}^{2}$ ( $D>100 \mathrm{~m})$. However, Rozhdestvensky N shows enhanced $\mathrm{S}$-band CPR inside its rim, with mean values of $0.95 \pm 0.49$, but displays average CPR values for areas outside its rim $(0.42 \pm 0.23$; Figure 4$)$. This relationship was first observed in the Chandrayaan-1 Mini-RF S-band data [Spudis et al., 2010] and now from the LRO Mini-RF data, it is evident in 


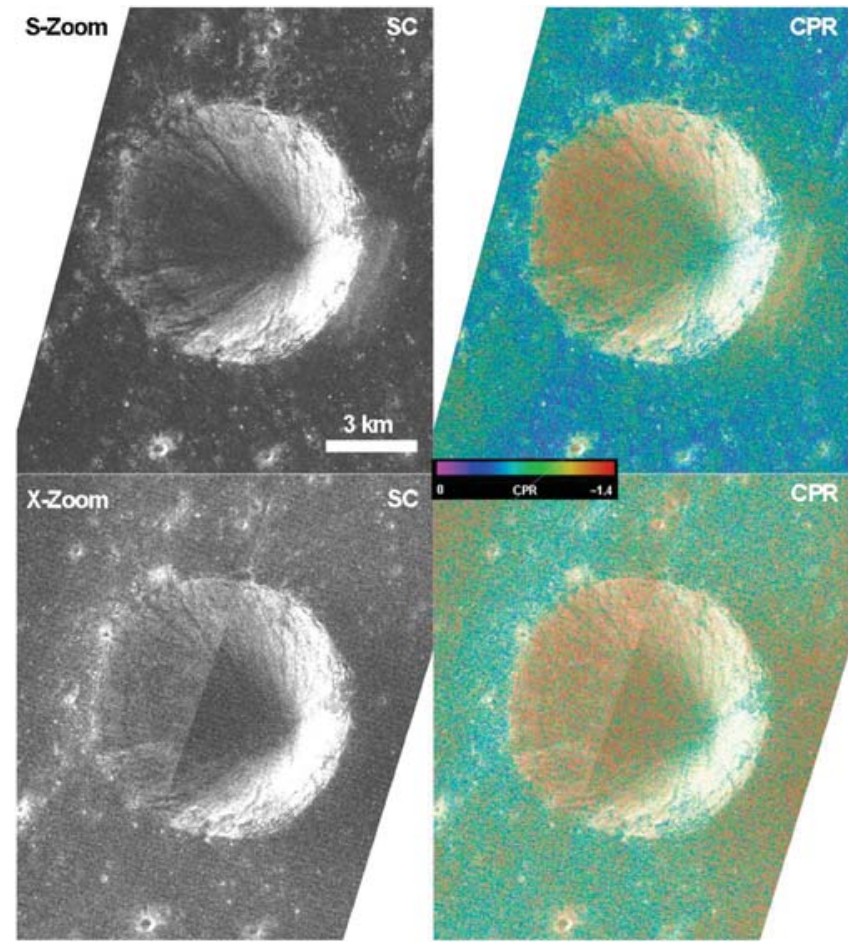

Figure 5. Rozhdestvensky $\mathrm{N}$ shows same CPR pattern in both S-band $(13 \mathrm{~cm})$ and $\mathrm{X}$-band $(4.3 \mathrm{~cm})$ radar wavelengths. Average CPR in the X-band data is higher because wavelength is shorter and rock frequency increases with decrease in fragment size.

both S-band and X-band images (Figure 5) and also in both left- and right-looking SAR directions (Figure 3) for both craters. The interiors of almost all of these anomalous craters are wholly or in large part in permanent sun shadow [e.g., Bussey et al., 2005; Bussey et al., 2010] and correlate with proposed locations of polar ice modeled on the basis of Lunar Prospector neutron spectrometer data [Elphic et al., 2007; Eke et al., 2009]. As discussed in Spudis et al. [2010], these relations are consistent with deposits of water ice in these craters.

[18] In our earlier studies of the Chandrayaan-1 Mini-RF data [Spudis et al., 2010], we identified 35 anomalous craters in the north polar area and 15 in the south polar region within $20^{\circ}$ of the pole (i.e., $\pm 70^{\circ}$ to $90^{\circ}$ ). We have reexamined both polar areas in the Mini-RF mosaics and find those same features as well as additional ones bringing the total number up to 43 anomalous craters in the north pole mosaic and 28 anomalous craters in the south pole mosaic (Figure 6; Table $\mathrm{S} 1)$. These craters vary in size from 3 to $20 \mathrm{~km}$ in diameter. All are topographically well defined, but lack detectable high-CPR ejecta deposits outside their rims. As an overall sample, anomalous craters do not appear to be located within specific terrains or geological settings and are found throughout the mapped polar area on crater floors, smooth plains fill, and within the intercrater areas. Normal fresh craters are found adjacent to the anomalous craters and scattered within clusters of same, suggesting that the origin of anomalous craters is not related to physical properties of the impact substrate. There are no obvious differences in the distribution of anomalous craters with respect to the near and far sides within the polar regions with the exception of an unusual concentration of small $(2-10 \mathrm{~km}$ diameter $)$ craters on the floor of Peary (Figures 7 and 8). This cluster of small craters, proposed to be Orientale basin secondaries [Campbell et al., 2010], all have interiors in permanent darkness and are extremely cold [<100 K; Paige et al., 2010b].

\section{Interpretation}

[19] High CPR on the Moon may be caused by one or both of two principal factors (1) large degrees of wavelength-scale surface roughness [e.g., Campbell, 2002, 2012] or (2) the presence of water ice [e.g., Nozette et al., 1996, 2001]. In the case of the former, geologically fresh surfaces (such as ejecta from young craters) create high degrees of surface roughness at wavelength-scales. Such roughness results in the creation of corner-reflectors that increase the amount of same-sense (double-bounce) reflections and thus, result in high CPR [Campbell, 2012]. Alternatively, if deposits of low-loss media (such as ice) exist on the Moon, they will also exhibit high CPR, in this case caused by both enhanced same-sense returns (through high degrees of volume scattering and corresponding multibounce) and from the coherent backscatter opposition effect (CBOE) [Hapke, 1990; Mishchenko, 1992]. The CBOE is an observational effect caused by viewing the ice deposits at zero phase, in which diffuse backscatter constructively interferes with itself to produce enhanced amounts of same-sense reflections (and hence, high CPR).

[20] As ice and regolith have similar dielectric properties, it has been suggested that they would be difficult to distinguish in radar returns [Fa et al., 2011]. Such difficulty would ensue even with deposits of relatively pure ice, although this purity factor has not been quantified and the specific amounts of contaminating debris that would erase the high-CPR signature is unknown. One line of evidence suggests that ice purity may be much less important than is commonly assumed. The three icy Galilean satellites all show varying amounts of CPR enhancement, and the degree of this enhancement seems to be correlated with optical albedo. Both Ganymede and Callisto are optically much darker (with optical albedo of 0.43 and 0.22 , respectively) than Europa (albedo of 0.67), indicating significant amounts of rocky debris in the surface of these outer bodies; analyses of optical spectra suggest that in Callisto, this contaminant may exceed $50 \%$ silicates by weight [Spencer, 1987]. Yet all three icy Galilean satellites show CBOE, with mean CPR values of 1.2 or greater [Ostro, 2002], increasing with increasing optical albedo. In addition, the polar deposits of Mercury exhibit a muted CBOE, thought to be caused by admixture of silicate particles into the ice regolith [Butler et al., 1993]. As the fraction of rock fragments increases, the CBOE decreases, but both Mercury and the icy Galilean satellites show that even significant amounts of silicates cannot totally remove the CBOE effect [Nozette et al., 1996]. These relations suggest that ice deposits on the Moon could contain significant amounts of particulate contamination yet still display high-CPR values caused by CBOE.

[21] The high CPR found around young fresh craters as described above for Main L (Figures 4 and 9) is best attributed to wavelength-sized (cm-scale) surface roughness, caused by the presence of a high density of fresh, angular 


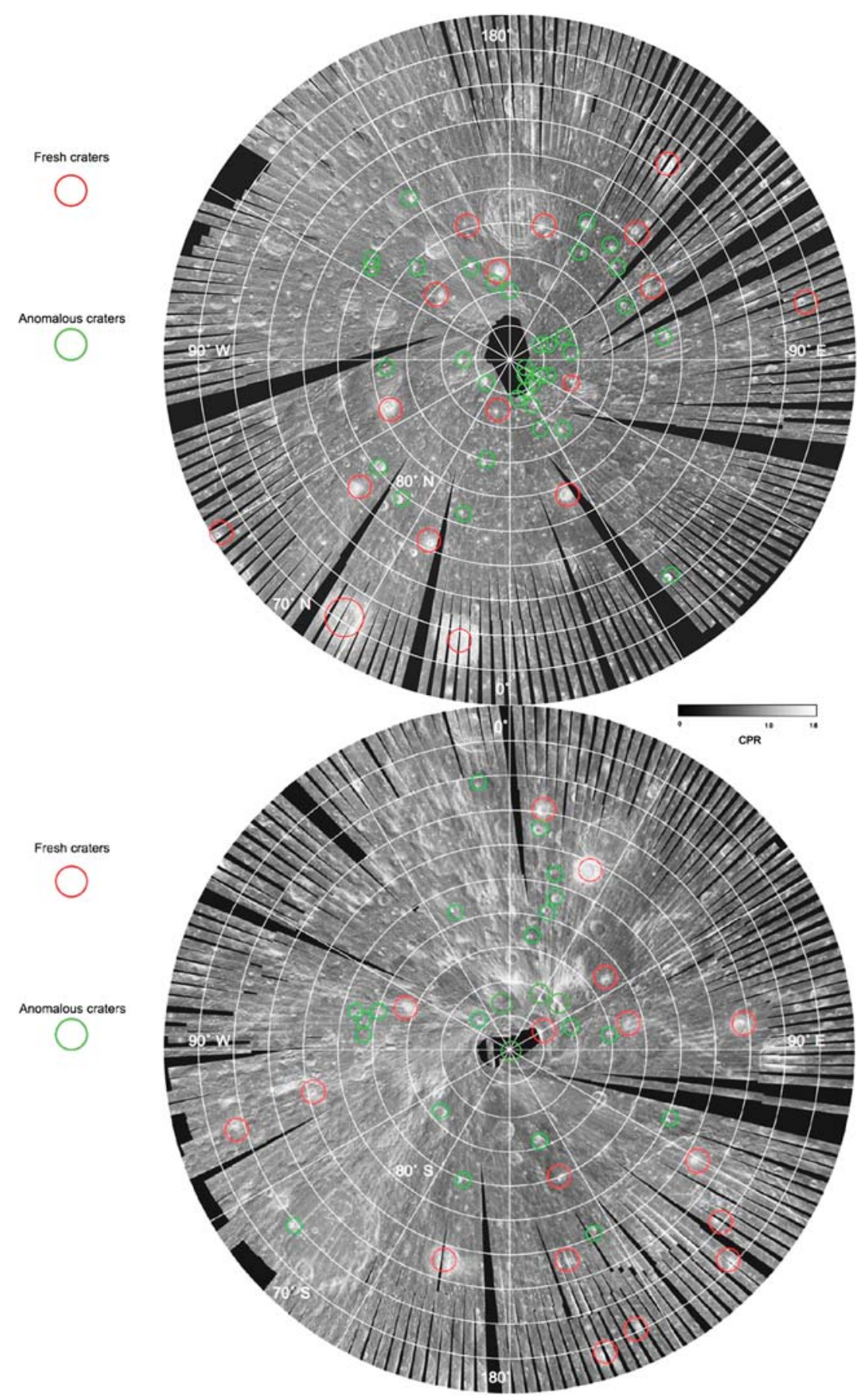

Figure 6. Location maps for the anomalous craters in north and south polar regions that have higher than average CPRs.

rocks at the surface or buried within the near-subsurface. Abundant rocks are expected in fresh crater deposits; a systematic study of the radar response to such features is presented in Carter et al. [2012]. As a crater ages, it erodes and becomes smoother with time, lessening the high-CPR signature of its deposits. We are currently undertaking detailed studies of block abundance around lunar craters with the aim of quantifying these relations and their changes with time [Baloga et al., 2012; Spudis et al., 2012].

[22] As lunar erosional processes from meteoritic bombardment affect both crater interiors and exteriors comparably, there is no obvious geological reason to expect the preservation of high degrees of blockiness inside a crater rim while eroding the outside deposits to background CPR levels. One possible mechanism to achieve this end might be the flow of debris under the influence of gravity from crater walls (i.e., mass wasting), as is seen in some craters such as Gardner (see Figure 10 and discussion below), but such debris flows are not common. Moreover, the pattern of high-CPR deposits in these polar anomalous craters is very consistent (Figure 5). In fresh crater interiors, the high-CPR deposits are patchy in distribution, corresponding to outcrops 


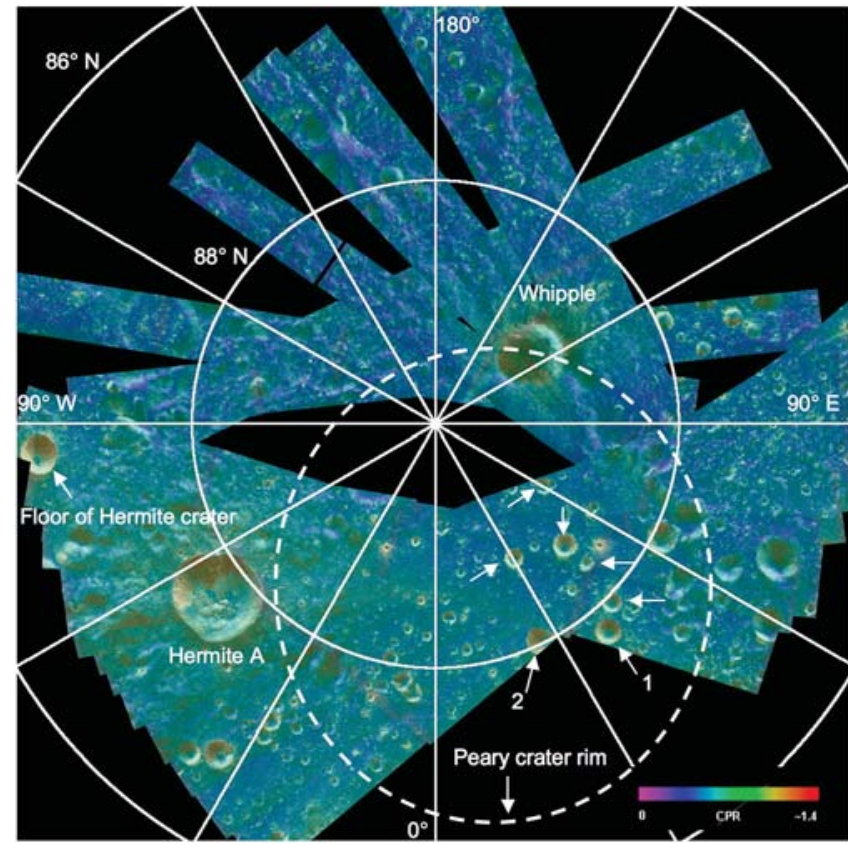

Figure 7. The north pole area of the Moon in S-band zoom CPR images (blue is low; yellow and red are high) from Mini-RF showing numerous, small "anomalous" craters (arrows) on the floor of Peary $\left(78 \mathrm{~km}\right.$ diameter; $88.6^{\circ} \mathrm{N}, 33^{\circ} \mathrm{E}$ ). The presence of "normal" fresh, young craters adjacent to the anomalous ones here suggests that the high CPR is not derived from properties of the Peary crater floor material. Craters labeled " 1 and 2 " on the floor of Peary and "Floor of Hermite crater" are analyzed by the scattering model (Table 3 ).

in the upper rim area, rock slides that extend down crater walls, and melt deposits and debris flows that occur on the crater floor [e.g., Carter et al., 2012]. The spatial uniformity of the high-CPR material in the polar anomalous craters suggests that some process other than normal mass wasting might be at work.

[23] We have identified several CPR anomalous craters outside of the polar regions. A global survey using the existing Mini-RF coverage (which covers about two thirds of the nonpolar regions of the Moon) [Bussey et al., 2011] shows a total of 88 nonpolar anomalous craters that have a ratio of mean exterior CPR to mean interior CPR of $\sim 0.4$ or more (Figure 8). While this is a fairly large number of anomalous craters, it is miniscule in comparison to the total abundance of 2-20 km craters within the same area (more than $\sim 25,000$, estimated from the global crater frequency distribution of Wilhelms [1987]).

[24] The observed distribution of craters classified as anomalous is unlikely to be due simply to random impacts on the lunar surface. The area of the two polar regions (combined) limited by the colatitude $\theta(\leq \pi / 2)$ as measured from either pole is given by

$$
A_{\mathrm{p}}=4 \pi(1-\cos \theta) R^{2}
$$

with the equatorial (nonpolar) region being

$$
A_{\mathrm{np}}=4 \pi \cos \theta R^{2} .
$$

[25] We assume that the probability of impact is directly proportional to the regional area. Thus, noting that there is near-complete radar coverage for the polar regions and radar coverage of approximately $3 / 5$ of the nonpolar area, the probability that a single random impact occurs in one or the other polar areas is

$$
q=\frac{A_{\mathrm{p}}}{A_{\mathrm{p}}+3 / 5 A_{\mathrm{np}}}=\frac{1-\cos \theta}{1-2 / 5 \cos \theta} .
$$

[26] Assuming all the impacts are independent, the probability of finding $k$ out of $N$, such impacts in the polar areas, is given by the binomial distribution $B(k, q ; N)$. Using $\theta=20^{\circ}$ to delineate the polar regions and $N=160$, the anticipated distribution of random impacts in the polar regions was calculated (Figure 9). If anomalous craters are randomly distributed on the surface of the Moon, one might expect 14-16 of those craters to be found in the two polar regions (combined), when in fact 72 have been identified (Figures 6 and 8). The cumulative binomial distribution indicates that the probability of finding 72 anomalous craters in the polar regions due to random impacts is significantly less than one in a million.

[27] The high CPR of anomalous craters in nonpolar regions cannot be caused by the presence of ice, as ice is not stable on lunar surfaces that receive direct sunlight during part of the lunar diurnal cycle. High-resolution LRO Camera (LROC) narrow-angle images [Robinson et al., 2010] of some of these features are available; a good example is the crater Gardner (also known as Vitruvius A; Figure 10). This $18 \mathrm{~km}$ diameter crater appears to be moderately old (late Imbrian) [Scott and Pohn, 1972], but does not display high CPR exterior to its rim. However, long (several kilometers) debris flows occur in the walls of this crater, creating extensive block fields that are likely to be responsible for the high CPR in the crater interior (Figure 10) [see also Campbell, 2012]. Direct evidence for the association of high CPR and surface roughness caused by debris flows from the crater rim is also found in the walls of Linné crater $\left(27.7^{\circ} \mathrm{N}, 11.8^{\circ}\right.$ E; $2.2 \mathrm{~km}$ diameter) in Mare Serenitatis [Baloga et al., 2012].

[28] The south polar region shows relations similar to those found in the north, except that it has more extensive low-CPR terrain and fewer anomalous high-CPR interior craters (Figure 6). Small patchy areas of high CPR are found in the floors of some permanently dark south polar craters, notably Shoemaker and Faustini. Spectra obtained in the ultraviolet from the LRO Lyman-Alpha Mapping Project instrument document the presence of water ice frost on the lunar surface in the permanently shadowed crater Haworth, just north of Shackleton [Gladstone et al., 2012]. Additionally, recent studies of the interior of Shackleton suggest that the patchy, high CPR on the walls of this crater [Thomson et al., 2012b] has characteristics consistent with a small amount of water ice mixed with regolith, in partial agreement with and extending the results of previous work [Nozette et al., 2001; Zuber et al., 2012].

[29] Additional information about the nature of anomalous crater deposits can be inferred by examining other data sets (Figure 11). The LRO Diviner thermal emission spectrometer on LRO mapped surface temperatures over the course of several years, yielding mean annual surface temperature maps [Paige et al., 2010a, 2010b]. This mapping shows large areas near both poles with surface temperatures less than 104 $\mathrm{K}$, the temperature below which water is permanently stable 


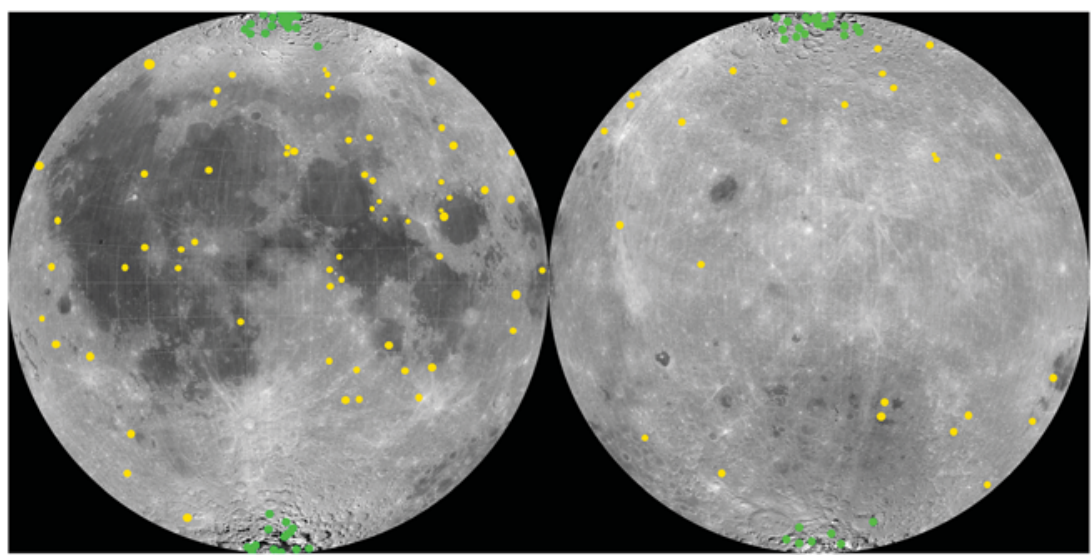

Figure 8. Global distribution of "anomalous" craters, defined as having an exterior/interior CPR ratio greater than 0.4. The anomalous craters in the polar areas (which have a much higher density) [Thomson et al., 2012a] are shown in green (see Figure 6 for polar view) while nonpolar anomalous craters are indicated in yellow. Left and right panels are Lambert Equal-Area projections centered at the equator and $0^{\circ}$ and $180^{\circ}$ longitude, respectively.

on the lunar surface. Moreover, water ice covered by a thin (few $\mathrm{cm}$ ) layer of regolith will be stable even at surface temperatures higher than $104 \mathrm{~K}$, which include large areas near the poles that receive occasional, partial, or grazing sunlight [Paige et al., 2010b]. The maps of Figure 11 show that of the 35 anomalous craters at the north pole, all occur within areas of permanent darkness as mapped from Kaguya topography and LRO wide-angle camera data [Bussey et al., 2010; McGovern et al., 2013]; 20 of them also are coincident with modeled locations of water ice from LP neutron data [Eke et al., 2009]. At the south pole, all 24 anomalous craters occur within permanent darkness and 14 of them are coincident with modeled locations of water ice from LP neutron data [Elphic et al., 2007]. These correspondences are consistent with the interpretation that the high-CPR materials are ice.

[30] The neutron spectrometer experiment flown on Lunar Prospector [Feldman et al., 1998, 2000; Lawrence et al., 2006] documented the occurrence of excess hydrogen (roughly a factor of three times more than the global mean concentration) at both poles. Because this instrument had low resolution (pixels of $45 \mathrm{~km}$ or larger), it could not resolve the much smaller interiors of many of the permanently shadowed craters near the poles (Figure 11) [Bussey et al., 2005, 2010]. However, forward-modeling by the Pixon method assumes that this hydrogen signal is associated with patches of ice within these dark craters [Elphic et al., 2007; Eke et al., 2009]. Such models produce patterns of ice distribution that often correspond closely to our maps of anomalous CPR craters (Figure 11) [Spudis et al., 2010]; slightly more than $50 \%$ of the anomalous craters in the north and south polar areas above $80^{\circ}$ latitude are coincident with modeled locations of water ice inferred from neutron spectroscopy [Elphic et al., 2007; Eke et al., 2009]. These observations do not prove that the polar craters with anomalous CPR values that we report here contain ice, but the correlation of multiple data sets (lighting, neutron models, and temperatures) with the locations of anomalous CPR craters supports this interpretation.

\section{Modeling the Radar Backscatter of Rough and Icy Craters}

[31] Further discrimination of icy and non-icy craters was carried out by applying an empirical scattering model that
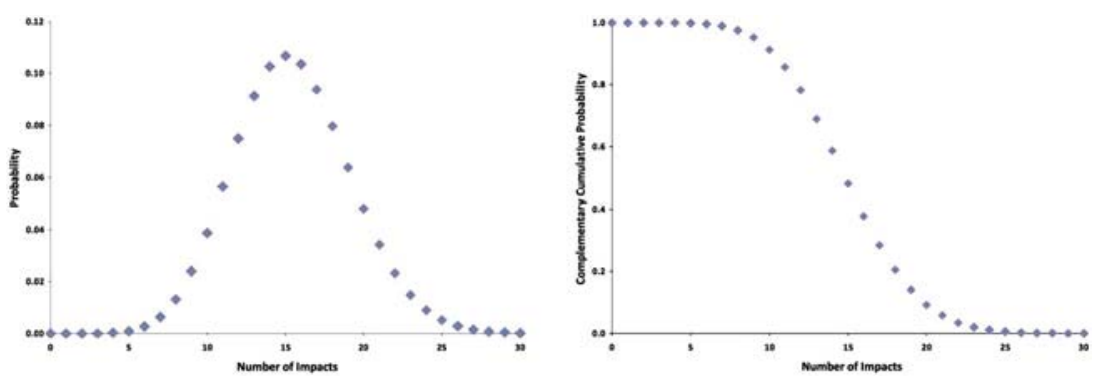

Figure 9. (left) Impact probability for polar locations, showing that 14-16 anomalous craters might be expected within $\pm 20^{\circ}$ of the poles if they were not somehow correlated to the unique environment of the poles. Seventy-two polar anomalous craters and 88 nonpolar anomalous craters have been identified. (right) Complementary cumulative probability associated with Figure 9 (left). Values on the $y$ axis indicate the probability of finding more than the number of impacts identified on the $x$ axis. The probability of finding more than 30 anomalous impact craters in the polar regions due strictly to random processes is effectively zero $(<0.0001)$. 


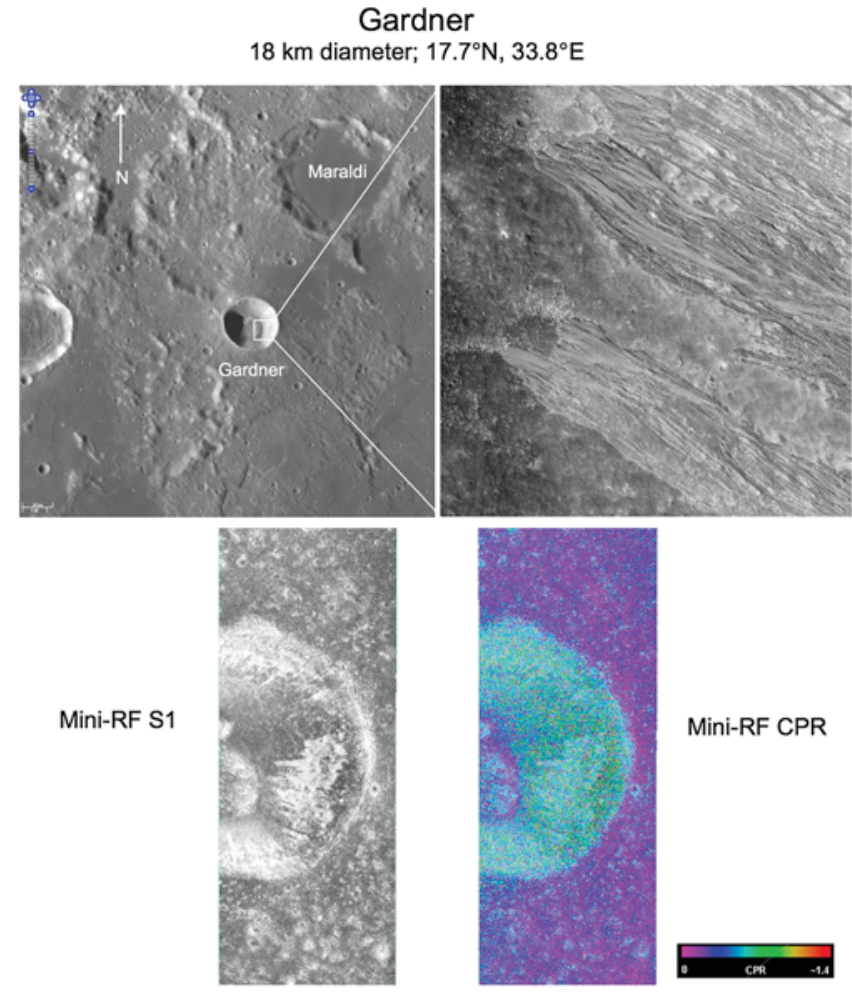

Figure 10. The lunar crater Gardner (also known as Vitruvius $\mathrm{A} ; 17.7^{\circ} \mathrm{N}, 33.8^{\circ} \mathrm{E} ; 18 \mathrm{~km}$ diameter), which is a multibounce crater, having high CPR inside its rim and low CPR outside. High-resolution optical NAC images show that this high CPR is caused by extensive debris flows on the walls and floor of the crater (right). These debris flows are very unusual; it is much more common for craters to become less blocky as they erode.

utilizes mixing of diffuse and specular components to describe the radar scattering behavior of ice-regolith mixtures [Thompson et al., 2011, 2012]. In this model, the specular component results from surface and near-subsurface layers that are smooth to a tenth of a radar wavelength for large ( $>10$ wavelengths) areas oriented perpendicular to the radar line-of-sight. The diffuse component, which is associated with either surface and near-surface roughness (wavelength-sized rocks) or composition (ice), is assumed to be uniformly bright, with backscatter being proportional to the cosine of the incidence angle. Specular scattering contributes only to opposite-sense circular (OC) echoes, while diffuse scattering contributes to both $\mathrm{OC}$ and same-sense circular (SC) echoes. Radar backscatter from the lunar surface is is assumed to have CPR of 2.0, as observed in the polar features of Mercury and Mars and the surfaces of the icy Galilean satellites of Jupiter [Muhleman et al., 1991; Harmon and Slade, 1992; Butler et al., 1993; Ostro, 2002]. The differences in appearance between the lunar and mercurian polar craters suggest that more ice is present on Mercury than on the Moon, probably a result of the higher cometary flux near Mercury compared with the Moon [e.g., Hartmann et al., 1981] and the fact that the higher surface gravity on Mercury $(\sim 0.3 \mathrm{~g})$ means that body will retain more water on its surface. The values assigned to these end-members are based on observations of fresh craters on the Moon, which have typical CPR values at $12.5 \mathrm{~cm}$ wavelength of $\sim 1$, with extreme examples showing CPR as high as 1.5-2.5 [Campbell, 2012] and on theoretical considerations of the CPR of pure ice reflectors [e.g., Peters, 1992].

[32] The scattering model of Thompson et al. [2011, 2012] postulated three different surface conditions that might result in high CPR on the Moon (1) "rough," corresponding to typical fresh young crater wavelength-scale surface roughness (e.g., rock fields); (2) "icy," composed of a thin dry regolith covering substantial ice deposits and/or a regolith with ice patches partially filling the radar pixels; and (3) a "multibounce" category (see Table 2 ). In each case, a specific pattern in the SC and OC signal strength accompanies the high CPR seen in the targets. This model uses the SC and OC echo enhancements, i.e., the ratios of observed powers for the crater interior and typical background terrain near these craters [Thompson et al., 2011, 2012]. For each feature, the typical SC, OC, and CPR values are determined for the crater in question and for a patch of background terrain of the same size nearby with a precision of about $5 \%$, as illustrated by their sizes in Figure 12. These craters are then classified according to the criteria given in Table 2, which in turn is based on the scatterplots shown in Figure 12.

[33] The examples selected for study included both normal (fresh) and anomalous craters from both polar regions. In addition, we examined several fresh impact features from nonpolar regions, including the nonpolar, Copernican-age crater Giordano Bruno $\left(35.9^{\circ} \mathrm{N}, 102.7^{\circ} \mathrm{E} ; 22 \mathrm{~km}\right.$ diameter). The backscatter of five fresh and eleven anomalous craters using the S-band zoom data was examined. Results indicate that rough craters, icy craters, and multibounce craters (i.e., those exhibiting high degrees of even number-bounce scattering) can be separated from each other on the basis of values of SC enhancement $(\alpha)$, OC enhancement $(\gamma)$, the ratio $(\alpha / \gamma)$, and their total power enhancement [Thompson et al., 2012]. The ratio $(\alpha / \gamma)$ is a proxy for CPR as $\operatorname{CPR}=(\alpha / \gamma) \mathrm{CPR}_{\mathrm{avg}}$. The total power enhancement is given by

$$
\begin{gathered}
\frac{\gamma \sigma_{\mathrm{OC}-\text { avg }}(\theta)+\alpha \sigma_{\mathrm{SC}-\text { avg }}(\theta)}{\sigma_{\mathrm{OC} \text {-avg }}(\theta)+\sigma_{\mathrm{SC}-\text { avg }}(\theta)}=\gamma\left(\frac{\sigma_{\mathrm{OC}-\text { avg }}(\theta)}{\sigma_{\mathrm{OC} \text {-avg }}(\theta)+\sigma_{\mathrm{SC}-\text { avg }}(\theta)}\right)+\alpha\left(\frac{\sigma_{\mathrm{SC}-\text { avg }}(\theta)}{\sigma_{\mathrm{OC}-\text { avg }}(\theta)+\sigma_{\mathrm{SC} \text {-avg }}(\theta)}\right) \\
=0.88 \gamma+0.12 \alpha
\end{gathered}
$$

modeled as a mixture of these specular and diffuse components. Diffuse scattering from rocky areas associated with fresh craters is assumed to have CPR of about 1.0; and ice where $\sigma_{\mathrm{OC} \text {-avg }}(\theta)$ and $\sigma_{\mathrm{SC} \text {-avg }}(\theta)$ are the average lunar $\mathrm{OC}$ and $\mathrm{SC}$ radar cross sections at the angle of incidence $\theta$ (given in 


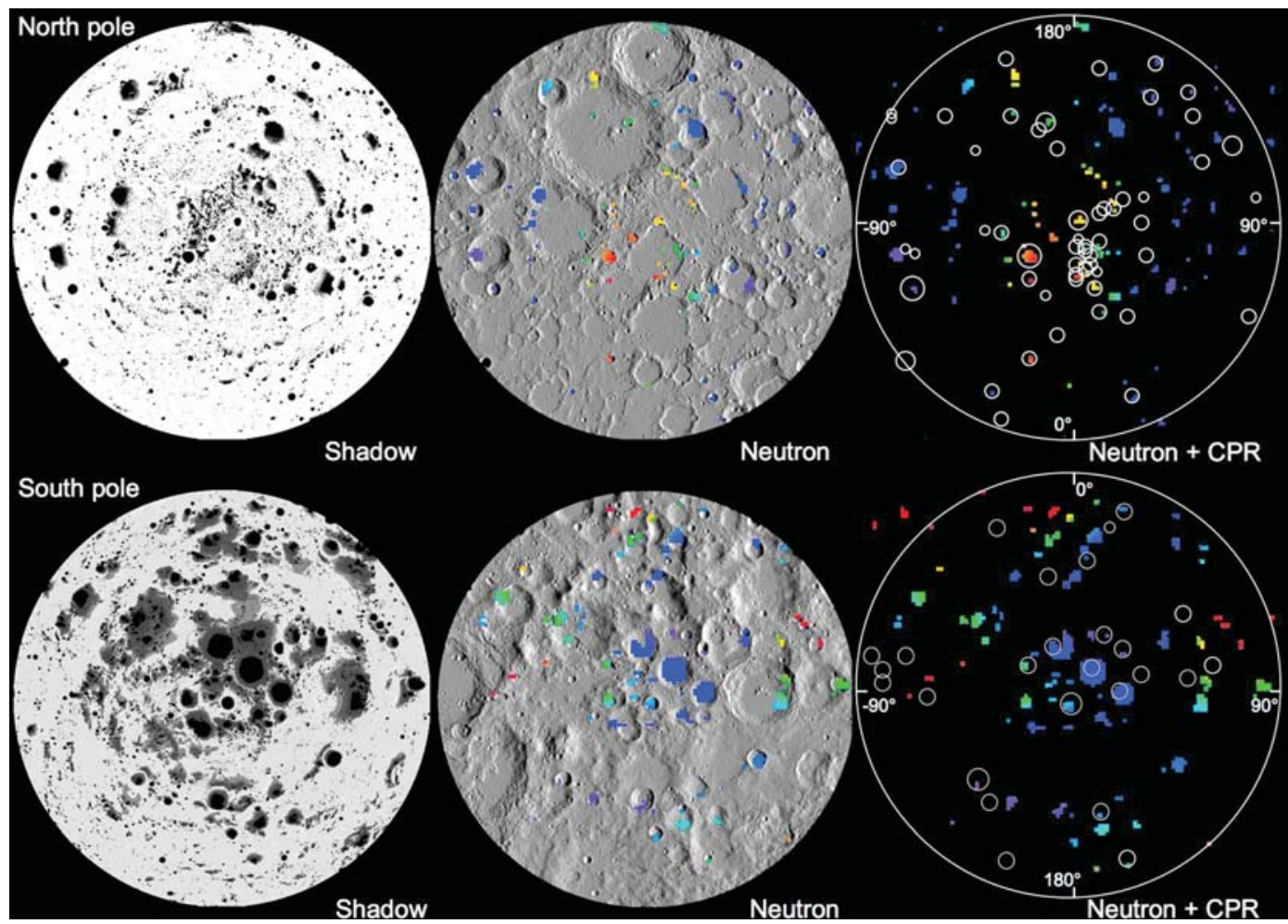

Figure 11. (left) Maps of the lunar poles $\left(80^{\circ}\right.$ latitude to pole) comparing the locations and distributions of permanent shadow (black areas), (middle) Pixon models of Lunar Prospector neutron spectrometer data (with purple and blue lowest water equivalent hydrogen and red high) [Elphic et al., 2007], and (right) Mini-RF anomalous CPR craters (white circles; see also Figure 7). North Pole maps at top; South Pole maps at bottom. Although not perfect, the three variables show reasonable correlation, supporting the idea that the anomalous polar craters may contain ice.

Thompson et al. [2011]). Here echo enhancements are the ratios of observed backscatter powers from the craters and their nearby backgrounds. Also,

$$
\mathrm{CPR}_{\text {avg }}=\sigma_{\mathrm{OC}-\mathrm{avg}}(\theta) / \sigma_{\mathrm{SC}-\mathrm{avg}}(\theta)
$$

[34] As noted above, three classes of craters (rough, icy, and multibounce) can be distinguished on the basis of the four parameters described above as shown in Figure 12 and Tables 2 and 3. All of the fresh craters found in nonpolar areas (Byrgius A, Giordano Bruno, and Euclides) plot as "rough" in this classification. Also, Main L, a typical polar fresh, young crater, falls into the "rough" category. A number of craters classified as polar anomalous (i.e., similar to Rozhdestvensky N (Figures 4 and 5), discussed above) from the Mini-RF CPR data fall into the "icy" category (either thin regolith over ice or ice patches within a larger radar pixel).

[35] Craters in the "multibounce" category are those that have surface geometries which would likely result in a multiple even number of corner reflections, not necessarily from ice. These have SC enhancements less than unity accompanied with $\mathrm{OC}$ enhancement less than 0.5 . These unusual craters may have extreme degrees of surface roughness as described by Campbell [2012] and might result from deposits similar to the granular debris flows seen in the walls of Gardner crater (Figure 10). An example of these multibounce craters is a small, unnamed crater north of Byrgius (Table 3), which contains very rough scree slopes of rocky debris as seen in LROC optical Narrow-Angle Camera (NAC) images. However, some multibounce craters in polar areas, which might contain ice deposits as well as rough surface terrain, do have interiors in permanent darkness and are extremely cold, according to Diviner thermal maps [Paige et al., 2010b]. Examples of this latter category include Shackleton [see also the results of Thomson et al., 2012b; Gladstone et al., 2012; Zuber et al., 2012] and a fresh crater on the floor of Rozhdestvensky (Figure 3; Table 3). It is possible for a fresh crater at the poles to contain ice if the timescales of ice accumulation (probably on the order of $10^{5}-10^{7}$ years) exceed the likely timescales of geological erosion of its surface ejecta deposits $\left(\sim 10^{8}-10^{9}\right.$ years $)$. Yet another possibility

Table 2. Separation of Crater Classes Based Upon Scattering Parameters $\alpha$ (SC Enhancement), $\gamma$ (OC Enhancement), the Ratio $\alpha / \gamma$ (a Proxy for CPR), and Total Power Enhancement ( $\Sigma$ of Thompson et al. $[2011,2012])^{\mathrm{a}}$

\begin{tabular}{lcccc}
\hline & $\begin{array}{c}\mathrm{SC} \\
\text { Enhancement } \\
\alpha\end{array}$ & $\begin{array}{c}\text { OC } \\
\text { Enhancement } \\
\gamma\end{array}$ & $\begin{array}{c}\text { Ratio } \\
\alpha / \gamma\end{array}$ & $\begin{array}{c}\text { Total Power } \\
\text { Enhancement } \\
\Sigma=0.12 \alpha+0.88 \gamma\end{array}$ \\
\hline Rough & $>1.5$ & $>1.0$ & $>1.25$ & $>1.0$ \\
Icy & $>1.0$ & $0.5<\gamma<1.0$ & $>1.5$ & $0.5<\Sigma<1.0$ \\
Multibounce & $<1.0$ & $<0.5$ & $>1.5$ & $<0.5$
\end{tabular}

${ }^{\mathrm{a}}$ See scatterplots (Figure 12). 

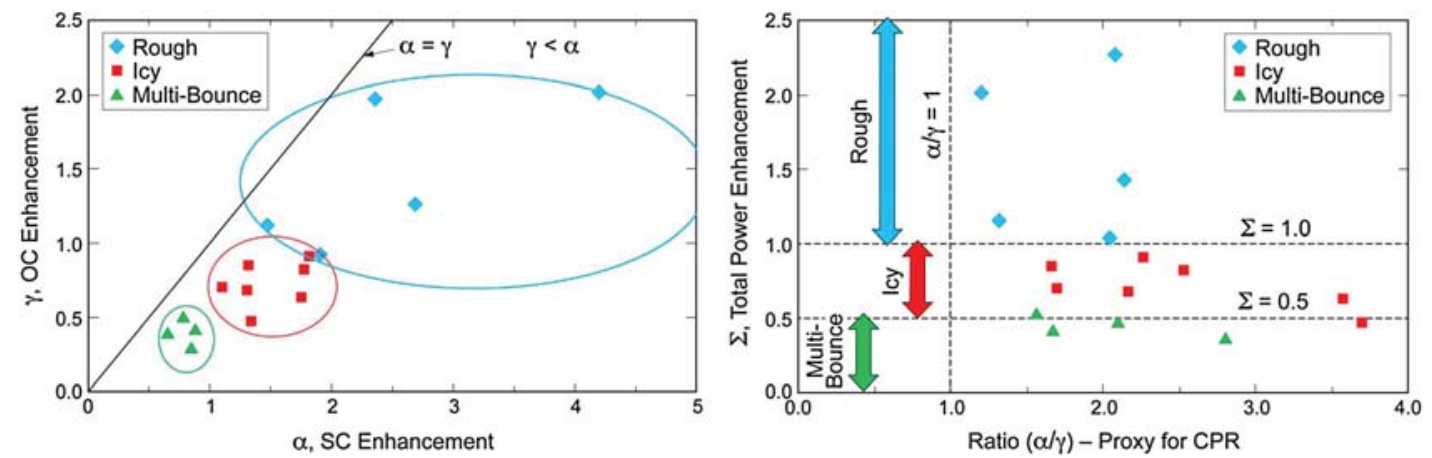

Figure 12. Classification of impact crater CPR based on the scattering model of Thompson et al. [2011]. Three classes of scattering are separated based upon their observed OC and SC scattering characteristicsrough, icy, and multibounce. The "anomalous" CPR craters seen in the Mini-RF maps of the polar regions all fall within either the icy or multibounce categories. See Table 2 for the definition of data classifications from Thompson et al. [2012] and Table 3 for the separation of crater classes based upon scattering parameters $\alpha$, (SC enhancement), $\gamma$ (OC enhancement), the ratio $\alpha / \gamma$ (a proxy for $\mathrm{CPR}$ ), and total power enhancement of Thompson et al. [2011, 2012]. Size of the symbols approximates their precision. Although there are a few craters where the separation between categories in the scatterplot of total power enhancement versus ratio is ambiguous, their separation in the scatter plot of $\gamma$ versus $\alpha$ is unambiguous.

is that a subset of these multibounce craters contains nearly pure ice, which would enhance their ice-like backscatter properties.

[36] The discrimination of craters based on the empirical scattering model of Thompson et al. [2011, 2012] is consistent with other observations of the properties of the polar anomalous craters, including their locations (Figure 11), lighting [Bussey et al., 2005, 2010] and thermal conditions [Paige et al., 2010b], and elevated hydrogen concentration signatures [Elphic et al., 2007; Eke et al., 2009], all of which suggest that deposits of ice are being detected by their radar characteristics in these polar craters. Although this comparison with modeling does not prove that these anomalous polar craters are ice-filled, the results are consistent with that possibility. The simultaneous use of the four variables (SC enhancement $(\alpha)$, OC enhancement $(\gamma)$, the ratio $(\alpha / \gamma)$, and their total power enhancement $(\Sigma)$ ) is a better discriminator between roughness and ice content than using CPR alone.

[37] If the high-CPR deposits in our sample of anomalous polar craters contain water ice, how much might be present?
To obtain volumetric coherent opposition backscatter (CBOE) [see Nozette et al., 2001] from these ices, the thickness of the deposit must be on the order of 100 wavelengths or more [Thompson et al., 2011] in order to have enough internal reflections to reverse the polarization. Thus, at S-band frequencies, the observed ice must be on the order of 10-20 m thick, as inclusion of silicate contaminants would increase attenuation in the ice and thus decrease these thicknesses by a factor of 2 to 3 . If the extent of the high interior CPR in the anomalous craters represents the lateral dimensions of a deposit with a thickness of 10-20 m, we estimate that the north polar area alone would contain about $6 \times 10^{8} \mathrm{~m}^{3}$ of ice. We do not know the physical characteristics of this ice - solid, dense ice, or "fairy castle" - snow-like ice would have similar radar properties. In possible support of the latter, the low radar albedo and lower than typical CPR values for nonanomalous terrain near the polar craters are $0.2-0.3$, somewhat lower than normal for the nonpolar highlands terrain of the Moon and are suggesting the presence of a low density, "fluffy" surface.

Table 3. Scattering Model Results [Thompson et al., 2012] ${ }^{\mathrm{a}}$

\begin{tabular}{|c|c|c|c|c|c|c|c|c|c|}
\hline Possible Category & Crater & Latitude & Longitude & Diameter $(\mathrm{km})$ & $\alpha$ & $\gamma$ & $\alpha / \gamma$ & $\Sigma$ & Classification \\
\hline Rough & Giordano Bruno & $35.9^{\circ} \mathrm{N}$ & $102.8^{\circ} \mathrm{E}$ & 22 & 4.2 & 2.0 & 2.1 & 2.3 & Rough \\
\hline Rough & Byrgius A & $24.5^{\circ} \mathrm{S}$ & $63.7^{\circ} \mathrm{W}$ & 19 & 2.4 & 2.0 & 1.2 & 2.1 & Rough \\
\hline Rough & Main L & $81.7^{\circ} \mathrm{N}$ & $23.2^{\circ} \mathrm{E}$ & 14 & 2.7 & 1.3 & 2.1 & 1.4 & Rough \\
\hline Rough & Euclides & $7.4^{\circ} \mathrm{S}$ & $29.5^{\circ} \mathrm{W}$ & 11 & 1.9 & 0.9 & 2.0 & 1.0 & Rough/ice patches \\
\hline Rough & Gardner & $17.7^{\circ} \mathrm{N}$ & $33.8^{\circ} \mathrm{E}$ & 18 & 2.0 & 0.8 & 2.7 & 0.9 & Ice patches \\
\hline Icy & Peary floor 1 & $88.1^{\circ} \mathrm{N}$ & $40^{\circ} \mathrm{E}$ & 4.5 & 1.1 & 0.7 & 1.7 & 0.7 & Regolith over ice \\
\hline Icy & Peary floor 2 & $88.2^{\circ} \mathrm{N}$ & $25^{\circ} \mathrm{E}$ & 7 & 1.8 & 0.8 & 2.3 & 0.9 & Ice patches \\
\hline Icy & Rozhdestvensky N & $84.0^{\circ} \mathrm{N}$ & $202.6^{\circ} \mathrm{E}$ & 9 & 1.3 & 0.8 & 1.7 & 0.9 & Ice patches \\
\hline Icy & Hermite floor 1 & $87.3^{\circ} \mathrm{N}$ & $85^{\circ} \mathrm{W}$ & 9 & 1.3 & 0.6 & 2.2 & 0.7 & Regolith over ice \\
\hline Icy & Hermite floor 2 & $87.3^{\circ} \mathrm{N}$ & $85^{\circ} \mathrm{W}$ & 9 & 1.8 & 0.7 & 2.5 & 0.8 & Regolith over ice \\
\hline Icy & Hermite A & $87.8^{\circ} \mathrm{N}$ & $47.1^{\circ} \mathrm{W}$ & 20 & 1.6 & 0.5 & 3.6 & 0.6 & Regolith over ice \\
\hline Icy & Erlanger & $87^{\circ} \mathrm{N}$ & $28.4^{\circ} \mathrm{E}$ & 10 & 1.3 & 0.4 & 3.7 & 0.5 & Regolith over ice \\
\hline Icy & Shackleton & $89.6^{\circ} \mathrm{S}$ & $132.3^{\circ} \mathrm{E}$ & 21 & 0.8 & 0.5 & 1.6 & 0.5 & Multibounce/ice \\
\hline Multibounce & North of Byrgius & $21.2^{\circ} \mathrm{S}$ & $64.5^{\circ} \mathrm{W}$ & 5 & 0.8 & 0.3 & 2.8 & 0.4 & Multibounce \\
\hline Multibounce & Rozhdestvensky floor 1 & $84.8^{\circ} \mathrm{N}$ & $172.5^{\circ} \mathrm{W}$ & 15 & 0.8 & 0.4 & 1.7 & 0.4 & Multibounce \\
\hline Multibounce & Rozhdestvensky floor 2 & $84.8^{\circ} \mathrm{N}$ & $172.5^{\circ} \mathrm{W}$ & 15 & 0.9 & 0.4 & 2.1 & 0.5 & Multibounce \\
\hline
\end{tabular}

${ }^{\mathrm{a}}$ Parameters and model correspondences given in Table 2 and shown in graphical form in Figure 12. Here $\alpha$ is the SC enhancement, $\gamma$ is the OC enhancement, and $\Sigma$ is total power enhancement given by equation 4 as $\Sigma=0.12 \alpha+0.88 \gamma$. 
Such properties are consistent with the target properties inferred for the LCROSS impact crater [Schultz et al., 2010]. If the deposits have the density of normal ice, they would have a total mass of about 600 million metric tons. It is important to note that these ice deposits would be present in addition to any ice that is admixed into the polar regolith at levels of a few to tens of percent. Such admixed ice is not visible to radar, as shown by the Mini-RF images of the south polar crater Cabaeus [Neish et al., 2011], which is known from LCROSS results to contain 5-10 wt.\% water ice [Colaprete et al., 2010].

\section{Conclusions}

[38] The LRO Mini-RF radar experiment has revealed the landscape of both lunar poles in two wavelengths, gathering polarimetric data for almost all of the polar terrain, including those areas previously hidden from Earth-view. We find that the radar signatures of the polar regions are very similar to typical highlands terrain elsewhere on the Moon, with a mature, low-CPR highlands surface and many superposed craters of varying sizes and ages.

[39] Our analysis indicates that the two types of high-CPR features are found in the lunar poles: fresh impact deposits with elevated CPR occurring interior to and exterior of the crater rim, and the "anomalous" deposits, which exhibit high-CPR only interior to the rims of certain craters. These polar anomalous deposits are found in permanently shadowed regions and are all very cold. Multiple lines of evidence including lighting, temperatures, neutron flux, UV, and S-band radar data when interpreted in combination suggest that these deposits are likely to be water ice. If this interpretation is correct, the extent and probable thickness of these deposits indicate that several hundred million tons of water may exist in the upper 2-3 $\mathrm{m}$ of the lunar surface at both poles. The presence of ice deposits makes the Moon an essential destination to learn how to access, process, and use this invaluable resource to create new space faring capabilities [Spudis and Lavoie, 2011].

[40] Acknowledgments. We thank the former NASA Operations Mission Directorate (Associate Administrator W. Readdy, R. Spearing, and J. Crusan) for initially funding the Mini-RF project and for critical support at several points in our long journey back to the Moon. This work was partly supported by the NASA NLSI Polar Science Team of The Johns Hopkins University Applied Physics Laboratory (Ben Bussey, PI) and by the LRO Science Team. Work carried out at the Jet Propulsion Laboratory, California Institute of Technology, (T. Thompson and E. Ustinov) was under a contract with the National Aeronautics and Space Administration. This work is Lunar and Planetary Institute Contribution Number 1751.

\section{References}

Arnold, J. R. (1979), Ice in the lunar polar regions, J. Geophys. Res., 84, 5659-5668.

Baloga, S. M., L. S. Glaze, and P. D. Spudis (2012), Inferred lunar boulder distributions at decimeter scales, Lunar Planet. Sci., 43, 1647.

Black, G. J., D. B. Campbell, and P. D. Nicholson (2001), Icy Galilean satellites: Modeling radar reflectivities as a coherent backscatter effect, Icarus, 151, 167-180.

Bussey, D. B. J., K. E. Fristad, P. M. Schenk, M. S. Robinson, and P. D. Spudis (2005), Constant illumination at the lunar North Pole, Nature, 434, 842.

Bussey, D. B. J., J. A. McGovern, P. D. Spudis, C. D. Neish, H. Noda, Y. Ishihara, and S.-A. Sørensen (2010), Illumination conditions of the south pole of the Moon derived using Kaguya topography, Icarus, $208(2), 558-564$.
Bussey, D. B. J., P. D. Spudis, and the Mini-RF Team (2011), New insights into lunar processes and history from global mapping by Mini-RF radar, Lunar Planet. Sci., 42, 2086.

Butler, B. J., D. O. Muhleman, and M. A. Slade (1993), Mercury: Full-disk images and the detection and stability of ice at the North Pole, J. Geophys. Res., 98, 15,003-15,023.

Campbell, B. A. (2002), Radar Remote Sensing of Planetary Surfaces, 331 pp., Cambridge Univ. Press, Cambridge UK.

Campbell, B. A. (2012), High circular polarization ratios in radar scattering from geologic targets, J. Geophys. Res., 117, E06008, doi:10.1029/ 2012JE004061.

Campbell, D. B., B. A. Campbell, L. M. Carter, J.-L. Margot, and N. J. S. Stacy (2006), No evidence for thick deposits of ice at the lunar south pole, Nature, 443, 835-837.

Campbell, B. A., L. M. Carter, D. B. Campbell, M. C. Nolan, J. F. Chandler, R. R. Ghent, B. R. Hawke, R. F. Anderson, and K. S. Wells (2010), Earthbased S-band radar mapping of the Moon: New views of impact melt distribution and mare physical properties, Icarus, 208, doi:10.1016/j. icarus.2010.03.011.

Carter, L. M., B. A. Campbell, B. R. Hawke, D. B. Campbell, and M. C. Nolan (2009), Radar remote sensing of nearside lunar pyroclastic deposits, J. Geophys. Res., 114, E11004, doi:10.1029/2009JE003406.

Carter, L. M., C. D. Neish, D. B. J. Bussey, P. D. Spudis, G. W. Patterson, J. T. Cahill, and R. K. Raney (2012), Initial observations of lunar impact melts and ejecta flows with the Mini-RF radar, J. Geophys. Res., 117, E00H09, doi:10.1029/2011JE003911.

Chin, G., et al. (2007), Lunar reconnaissance orbiter overview: The instrument suite and mission, Space Sci. Rev., 129, 391-419.

Colaprete, A., et al. (2010), Detection of water in the LCROSS ejecta plume, Science, 330(6003), 463-468.

Eke, V. R., L. F. A. Teodoro, and R. C. Elphic (2009), The spatial distribution of polar hydrogen deposits on the Moon, Icarus, 200, 12-18.

Elphic, R. C., V. R. Eke, L. F. A. Teodoro, D. J. Lawrence, and D. B. J. Bussey (2007), Models of the distribution and abundance of hydrogen at the lunar south pole, Geophys. Res. Lett., 34, L13204, doi:10.1029/2007GL029954.

Fa, W., M. A. Wieczorek, and E. Heggy (2011), Modeling polarimetric radar scattering from the lunar surface: Study on the effect of physical properties of the regolith layer, J. Geophys. Res., 116, E03005, doi:10.1029/ $2010 J E 003649$.

Feldman, W. C., S. Maurice, A. B. Binder, B. L. Barraclough, R. C. Elphic, and D. J. Lawrence (1998), Fluxes of fast and epithermal neutrons from lunar prospector: Evidence for water ice at the lunar poles, Science, 281, 1496-1500.

Feldman, W. C., D. J. Lawrence, R. C. Elphic, B. L. Barraclough, S. Maurice, I. Genetay, and A. B. Binder (2000), Polar hydrogen deposits on the Moon, J. Geophys. Res., 105(E2), 4175-4195.

Gladstone, G. R., et al. (2012), Far-ultraviolet reflectance properties of the Moon's permanently shadowed regions, J. Geophys. Res., 117, E00H4, doi:10.1029/2011JE003913.

Hapke, B. (1990), Coherent backscatter and the radar characteristics of outer planet satellites, Icarus, 88, 407-417.

Harmon, J. K., and M. A. Slade (1992), Radar mapping of Mercury: Fulldisk Doppler delay images, Science, 258, 640-643.

Hartmann, W. K., et al. (1981), Chronology of planetary volcanism by comparative studies of planetary cratering, in Basaltic Volcanism on the Terrestrial Planets, pp. 1050-1129, Pergamon Press, NY.

Heggy, E., S. M. Clifford, A. Younsi, J. L. Miane, R. Carley, and R. V. Morris (2007), On the dielectric properties of dust and ice-dust mixtures: Experimental characterization of the Martian polar layered deposits analog materials, Lunar Planet. Sci., 38, 1756.

Hörz, F., R. A. F. Grieve, G. Heiken, P. D. Spudis, and A. Binder (1991), Lunar surface processes, in Lunar Sourcebook: A User's Guide to the Moon, Chapter 4, edited by G. Heiken, D. Vaniman, and B. French, pp. 61-120, Cambridge Univ. Press, Cambridge, New York.

Lawrence, D. J., W. C. Feldman, R. C. Elphic, J. J. Hagerty, S. Maurice, G. W. McKinney, and T. H. Prettyman (2006), Improved modeling of lunar prospector neutron spectrometer data: Implications for hydrogen deposits at the lunar poles, J. Geophys. Res., 111, E08001, doi:10.1029/2005JE002637.

Lucchitta, B. K. (1978), Geologic map of the north side of the Moon: U.S. Geological Survey Miscellaneous Geologic Investigations Map I-1062, scale 1:5000 000 .

McGovern, J. A., D. B. J. Bussey, B. T. Greenhagen, D. A. Paige, J. T. S. Cahill, and P. D. Spudis (2013), Mapping and characterization of non-polar permanent shadows on the lunar surface, Icarus, 223, 566-581.

Mishchenko, M. I. (1992), The angular width of the coherent backscatter opposition effect: An application to icy outer planet satellites, Astrophys. Space Sci., 194(2), 327-333, doi:10.1007/BF00644001.

Muhleman, D. O., B. J. Butler, A. W. Grossman, and M. A. Slade (1991), Radar images of Mars, Science, 253, 1508-1513. 


\section{SPUDIS ET AL.: EVIDENCE FOR ICE ON THE MOON}

Neish, C. D., D. B. J. Bussey, P. Spudis, W. Marshall, B. J. Thomson, G. W. Patterson, and L. M. Carter (2011), The nature of lunar volatiles as revealed by Mini-RF observations of the LCROSS impact site, J. Geophys. Res., 116, E01005, doi:10.1029/2010JE003647.

Nozette, S., C. Lichtenberg, P. D. Spudis, R. Bonner, W. Ort, E. Malaret, M. Robinson, and E. M. Shoemaker (1996), The Clementine bistatic radar experiment, Science, 274, 1495-1498.

Nozette, S., P. D. Spudis, M. Robinson, D. B. J. Bussey, C. Lichtenberg, and R. Bonner (2001), Integration of lunar polar remote-sensing data sets: Evidence for ice at the lunar south pole, J. Geophys. Res., 106(E19), $23,253-23,266$

Nozette, S., et al. (2010), The lunar reconnaissance orbiter miniature radio frequency (Mini-RF) technology demonstration, Space Sci. Rev., 150, 285-302.

National Research Council (2007), The Scientific Context for Exploration of the Moon, 107 pp., National Academy of Science Press, Washington DC.

Ostro, S. J. (2002), Planetary radar astronomy, in The Encyclopedia of Physical Science and Technology, 3rd ed., edited by R. A. Meyers, pp. 295-328, Academic Press, New York.

Paige, D. A., et al. (2010a), The Lunar Reconnaissance Orbiter Diviner Lunar Radiometer Experiment, Space Sci. Rev., 150(1-4), 125-160.

Paige, D. A., et al. (2010b), Diviner Lunar Radiometer observations of cold traps in the Moon's south polar region, Science, 330, 479-482.

Peters, K. J. (1992), Coherent-backscatter effect: A vector formulation accounting for polarization and absorption effects and small or large scatterers, Phys. Rev. B, 46(2), 801-812.

Raney, R. K. (2007), Hybrid polarity SAR architecture, IEEE Trans. Geosci. Remote Sens., 45(11), 3397-3404.

Raney, R. K., et al. (2011), The lunar mini-RF radars: Hybrid polarimetric architecture and initial results, Proc. IEEE, 99(5), 808-823, doi:10.1109/ JPROC.2010.2084970.

Robinson, M. S., et al. (2010), Lunar Reconnaissance Orbiter Camera (LROC) Instrument Overview, Space Sci. Rev., 150, 81-124, doi:10.1007/s11214010-9634-2.

Schultz, P. H., B. Hermalyn, A. Colaprete, K. Ennico, M. Shirley, and W. S. Marshall (2010), The LCROSS cratering experiment, 330, 6003, $468-472$

Scott, D. H., and H. A. Pohn (1972), Geologic map of the Macrobius quadrangle of the Moon: U.S. Geol. Survey Misc. Geol. Inv. Map I-799, scale $1: 1,000,000$

Shoemaker, E. M., M. S. Robinson, and E. M. Eliason (1994), The south pole region of the Moon as seen by Clementine, Science, 266, 1851-1854.

Simpson, R. A., and G. L. Tyler (1999), Reanalysis of Clementine bistatic radar data for the lunar south pole, J. Geophys. Res., 104, 3845-3862.

Spencer, J. R. (1987), Thermal segregation of water ice on the Galilean satellites, Icarus, 69, 297-313.

Spudis, P. D., and A. R. Lavoie (2011), Using the resources of the Moon to create a permanent cislunar space faring system. Space 2011 Conf. and Expos., Amer. Inst. Aeronautics Astronautics, Long Beach CA, AIAA 2011-7185, 24 pp.
Spudis, P. D., R. A. Reisse, and J. J. Gillis (1994), Ancient multi-ring basins on the Moon revealed by Clementine laser altimetry, Science, 266 $1848-1851$

Spudis, P. D., B. Bussey, J. Plescia, J.-L. Josset, and S. Beauvivre (2008), Geology of Shackleton crater and the south pole of the Moon, Geophys. Res. Lett., 35, L14201, doi:10.1029/2008GL034468.

Spudis, P. D., S. Nozette, B. Bussey, K. Raney, H. Winters, C. Lichtenberg, W. Marinelli, J. Crusan, and M. M. Gates (2009), Mini-SAR: An imaging radar experiment for the Chandrayaan-1 mission to the Moon, Curr. Sci. India, 96(4), 533-539.

Spudis, P. D., et al. (2010), Initial results for the north pole of the Moon from Mini-SAR, Chandrayaan-1 mission, Geophys. Res. Lett., 37, L06204, doi:10.1029/2009GL042259.

Spudis, P. D., S. M. Baloga, L. S. Glaze, V. Dixit, S. M. Pantone, and I. Juvanescu (2012), Radar scattering and block size properties of lunar crater ejecta from Mini-RF and LROC NAC data, Lunar Planet. Sci. 43,1461 .

Stacy, N. J. S., D. B. Campbell, and P. G. Ford (1997), Arecibo radar mapping of the lunar poles: A search for ice deposits, Science, 276, 1527-1530.

Thompson, T. W., E. A. Ustinov, and E. Heggy (2011), Modeling radar scattering from icy lunar regoliths at $13 \mathrm{~cm}$ and $4 \mathrm{~cm}$ wavelengths, J. Geophys. Res., 116, E01006, doi:10.1029/2009JE003368.

Thompson, T. W., E. A. Ustinov, P. D. Spudis, and B. W. Fessler (2012), Modeling of radar backscattering from icy and rough lunar craters, Lunar Planet. Sci., 43, 1069.

Thomson, B. J., D. B. J. Bussey, J. T. S. Cahill, C. D. Neish, R. Kirk, G. W. Patterson, R. K. Raney, and P. D. Spudis (2012a), Excess numbers of enhanced CPR craters in the lunar polar regions, Lunar Planet. Sci., 43, 2104

Thomson, B. J., et al. (2012b), An upper limit for ice in Shackleton crater as revealed by LRO Mini-RF orbital radar, Geophys. Res. Lett., 39, L14201, doi:10.1029/2012GL052119.

Vasavada, A. R., D. A. Paige, and S. E. Wood (1999), Near-surface temperatures on Mercury and the Moon and the stability of polar ice deposits, Icarus, 141, 179-193.

Watson, K., B. Murray, and H. Brown (1961), On the possible presence of ice on the Moon, J. Geophys. Res., 66, 1598-1600.

Whitaker, E. A. (1999), Mapping and Naming the Moon: A History of Lunar Cartography and Nomenclature, 242 pp., Cambridge Univ. Press, Cambridge UK

Wilhelms, D. E. (1987), The Geologic History of the Moon. U.S. Geol. Survey Prof. Paper 1348, 302 pp.

Wilhelms, D. E., Howard K. A., and Wilshire H. G. (1979), Geologic map of the south side of the Moon, U. S. Geol. Survey Misc. Invest. Ser. Map I1162 , scale $1: 5,000,000$.

Zisk, S. H., G. H. Pettengill, and G. W. Catuna (1974), High-resolution radar maps of the lunar surface at 3.8-cm wavelength, Moon, 10, 17-50.

Zuber, M. T., et al. (2012), Constraints on the volatile distribution within Shackleton crater at the lunar south pole, Nature, 486, 378-381. 